\title{
Efficient masking of plant genomes by combining kmer counting and curated repeats
}

Bruno Contreras-Moreira 1*, Carla V Filippi 1,2,3, Guy Naamati 1, Carlos García Girón 1, James E Allen 1, Paul Flicek 1

1 European Molecular Biology Laboratory, European Bioinformatics Institute, Wellcome Genome Campus, Hinxton, Cambridge CB10 1SD, UK

2 Instituto de Biotecnología, Centro de Investigaciones en Ciencias Veterinarias y Agronómicas (CICVyA), Instituto Nacional de Tecnología Agropecuaria (INTA); Instituto de Agrobiotecnología y Biología Molecular (IABIMO), INTA-CONICET Nicolas Repetto y Los Reseros s/n (1686), Hurlingham, Buenos Aires, Argentina

3 Consejo Nacional de Investigaciones Científicas y Técnicas-CONICET, Ciudad Autónoma de Buenos Aires, Argentina

* Corresponding author: bcontreras@ebi.ac.uk

\section{li. Summary/Abstract}

The annotation of repetitive sequences within plant genomes can help in the interpretation of observed phenotypes. Moreover, repeat masking is required for tasks such as whole-genome alignment, promoter analysis or pangenome exploration. While homology-based annotation methods are computationally expensive, k-mer strategies for masking are orders of magnitude faster. Here we benchmark a two-step approach, where repeats are first called by k-mer counting and then annotated by comparison to curated libraries. This hybrid protocol was tested on 20 plant genomes from Ensembl, using the kmer-based Repeat Detector (Red) and two repeat libraries (REdat and nrTEplants, curated for this work). We obtained repeated genome fractions that match those reported in the literature, but with shorter repeated elements than those produced with conventional annotators. Inspection of masked regions overlapping genes revealed no preference for specific protein domains. Half of Red masked sequences can be successfully classified with 

made available under aCC-BY 4.0 International license.

nrTEplants, with the complete protocol taking less than $2 \mathrm{~h}$ on a desktop Linux box. The repeat library and the scripts to mask and annotate plant genomes can be obtained at https://github.com/Ensembl/plant-scripts .

\section{Key Words}

Plant genomes, repetitive sequences, transposable elements, NLR genes, sequence masking, annotation 


\section{Introduction}

Besides genes, plant genomes contain intergenic sequences, with increasing repetitive sequences as genome size grows. The growth in repeat content is roughly linear up to a genome size of $10 \mathrm{Gbp}$, including most known angiosperms, and then plateaus (1). The repetitive fraction of the genome is made up of low-copy repeats, simple repeats (such as satellite DNA), and transposable elements (TEs), which were discovered by Barbara McClintock in maize (2).

TEs can be important to explain observed phenotypes or domestication (see for instance reference (3) ) and are used as a source of genetic variability in breeding programs (4). The hypothesis is that the copy-and-paste and cut-and-paste mechanisms of TEs might leave footprints in the genome and can potentially affect the expression, regulation or coding sequence of neighboring genes. Moreover, TEs are increasingly receiving attention in studies tackling plant pangenomes (see for instance (5)). According to the Wicker classification, plant TEs can be classified either as class I RNA retrotransposons or class II DNA transposons (6). Software resources such as RepeatMasker (RM) (7), RepBase (8) or RepetDB (9) that are typically used to annotate TEs in plant genomes use the Wicker classification rules (see (10) for a software review). However, it has been reported that disease resistance $(R)$ genes, which are of great interest for plant breeding, are often masked by these annotation strategies (11). Furthermore, in our experience creating the Ensembl Plants resources, repeat annotation jobs can take up to several days on a computer cluster depending on the genome size. Moreover, the RepBase library requires subscription.

In addition to the intrinsic biological value of TEs, the annotation of repeats can be used to estimate assembly quality (12), as an alternative to gene completeness (13). For other genomic analyses, the bulk of repeated sequences may disrupt common computational genomic analyses and are thus often masked out without any classification attempt. For instance, whole-genome alignment (WGA), promoter analysis or the construction of graph genomes require the computation of resulting in frequency tables of k-mers, which are 
nucleotide words of size $\mathrm{k}$. If repeated sequences are not masked, the frequency tables are severely biased and can affect the obtained results (see for instance (14)). While annotation approaches based on sequence similarity are computationally expensive, k-mer masking strategies are orders of magnitude faster (15-18) and, in our experience, much better to prepare WGAs of barley and wheat cultivars using LASTZ (19).

In this paper we benchmark a two-step approach for the annotation of plant repeated sequences. First, repeats are called by k-mer counting with the Repeat Detector (Red). Second, the discovered repeated sequences are annotated by sequence alignment to a newly curated metacollection of repeats called nrTEplants. We compare this approach to the conventional RM pipeline, with both nrTEplants and the REdat (20) library, on a set of 20 angiosperms from Ensembl. We then compare their performance and discuss the results. The nrTEplants library is bundled with scripts to mask and annotate genomes of angiosperms, enabling interoperability, reuse and reproducible analyses (21). 


\section{Materials and methods}

\subsection{Plant repeat libraries}

We searched the literature for plant-specific libraries of repeated sequences and selected those in Table 1. While some are specific for a species or repeat family, others comprise repeats from mixed species, such as REdat from PGSB PlantsDB (20) or RepetDB (9). FASTA files with nucleotide sequences of repeats were downloaded from the indicated URLs or obtained from the authors.

\subsection{Plant cDNA sequences}

Plant species in Ensembl Plants release 46 (November 2020) (22) were ranked in terms of the number of proteins reviewed in Uniprot by February 22nd, 2020 (23). This was considered as an indicator of annotation quality. A list of the best annotated dicot and monocot species was produced, including Arabidopsis thaliana, Brassica napus, Glycine max, Helianthus annuus, Medicago truncatula, Phaseolus vulgaris, Populus trichocarpa, Solanum lycopersicum, Vitis vinifera, Brachypodium distachyon, Hordeum vulgare, Oryza sativa subsp. japonica, Sorghum bicolor and Zea mays. Transcripts from these species were downloaded with the script ens_sequences.p/ from https://github.com/Ensembl/plant-scripts.

\subsection{Sequence clustering}

All cDNA and TE sequences were clustered with GET_HOMOLOGUES-EST version 10042020 (24). This software runs BLASTN and the MCL algorithm, and computes coverage by combining local alignments. The sequence identity cutoff was $95 \%$ and the alignment coverage $75 \%$. Global variables in script get_homologues-est.pl lines L36-7 were set to \$MAXSEQLENGTH = 55000 and \$MINSEQLENGTH = 90. Sequences were clustered with command get_homologues-est.pl $-d$ repeats $-m$ cluster $-M$-t 0 -i 100 . Check https://github.com/Ensembl/plant tools/tree/master/bench/repeat libs for more details. 


\subsection{Positive control Pfam domains}

A list of 22 Pfam domains found in transposable elements was curated (25), available at https://github.com/Ensembl/plant tools/blob/master/bench/repeat libs/control pos.list

\subsection{Negative control: Pfam domains of disease resistance $(R)$ genes}

For the identification and curation of Pfam domains encoded by R genes, the following steps were performed. First, a set of 153 protein sequences encoded by reference R genes (i.e. cloned and/or with robust evidence) was retrieved from http://www.prgdb.org/prgdb (26). Second, the program hmmscan from HMMER v3.2.1 (27) was used for initial Pfam domain identification (v32, default settings), yielding a total of 60 Pfam hidden Markov models. The observed order and combinations of Pfam domains were retrieved. Third, the proteins of 6 plant species (A. thaliana, B. distachyon, G. max, $H$. annuus, $H$. vulgare and Triticum aestivum) containing at least one of the 60 pfam previously identified were retrieved from https://plants.ensembl.org/biomart/martview (28). These proteins were subsequently filtered, retaining only those with the ordered combinations of Pfam domains observed in the reference $\mathrm{R}$ proteins, and were considered as potential $\mathrm{R}$ proteins (428 in A. thaliana, 577 in B. distachyon, 1,008 in G. max, 849 in $H$. annuus, 838 in $H$. vulgare, and 3,607 in $T$. aestivum). From the initial set of Pfam domains, only 43 were consistently identified in our final panel of potential R gene's encoded proteins, and used as negative control. Note that one of them (PF02892, zf-BED) is often found in transposases (25). The list is available at https://github.com/Ensembl/plant tools/blob/master/bench/repeat libs/control neg NLR.list.

\subsection{De novo annotation of nucleotide-binding and leucine-rich repeat immune receptor (NLR) genes}

The NLR-annotator software was used for de novo annotation of NLR genes, which are the most abundant $R$ genes characterized to date, in whole genome sequences (29). Briefly, the set of 20 plant genomes were dissected into fragments of $20 \mathrm{~kb}$ length, with $5 \mathrm{~kb}$ overlaps, using the ChopSequence.jar routine. The cut sequences were then scanned to find 
NLR-associated sequence motifs using NLR-Parser.jar. Finally, NLR-Annotator.jar was used to integrate the annotated motifs and retrieve the actual NLR loci in BED format. In order to compute intersections with repeats only NLR loci with overlap > 50bp were considered. Moreover, to account for the fact that the tested masking strategies cover different fractions of the genome, odd ratios of NLR masking were computed with Equation 1:

odds ratio $=\frac{\text { masked } N L R \text { space } / \text { masked genome space }}{N L R \text { space } / \text { genome space }}$

\subsection{Masking and annotation of repeats in plant genomes}

RepeatMasker version v4.0.5 and a fork of Repeat Detector (Red) v2.0 adapted for

Ensembl, available at https://github.com/EnsemblGenomes/Red, were used to call repeats in plant genomes with libraries REdat v9.3 and nrTEplanst v0.3. Red was called from script

https://github.com/Ensembl/plant-scripts/blob/master/repeats/Red2Ensembl.py, which can

run several sequences in parallel and feed the results into a Ensembl core database (30). In addition, minimap2 version 2.17-r974-dirty (31) was used to annotate repeats called by Red with sequences from nrTEplants as follows: minimap2 -K100M --score-N 0 -x map-ont nrTEplants. Minimap2 is called from script

https://github.com/Ensembl/plant-scripts/blob/master/repeats/AnnotRedRepeats.py, which parses its output to annotate the repeats. By default only repeats with length $>90 \mathrm{bp}$ are processed. TE classification terms are parsed from the FASTA header of the library after a hash char (\#, i.e. 'RLG_43695:mipsREdat_9.3p_ALL\#LTR/Gypsy'). Elapsed runtime and RAM consumption was obtained with command time $-v$.

Genomic intersections among repeated sequences called by Red and RM and genomic features (ie protein-coding genes, exons, proximal downstream/upstream 500bp windows, NLR loci) were computed with Bedtools (v2.26.0) (32) using bedtools intersect -a bed/genes.bed -b repeat.bed -sorted -wo. To avoid redundancy, exons were extracted from Ensembl canonical transcripts (see http://plants.ensembl.org/info/website/glossary.html). Neighbor genes were also subtracted from downstream/upstream windows. 


\subsection{K-mer analysis of repeats in downstream/upstream windows}

Repeats overlapping proximal downstream/upstream 500bp windows were extracted using bedtools intersect analysis and the sequences cut with bedtools getfasta. Canonical K-mers with $\mathrm{K}=[16,21,31]$ were counted with Jellyfish v2.3.0 (33) with commands jellyfish-linux count $-C-m K-s 2 G$-t 4 and jellyfish-linux dump -L 20.

\subsection{Enrichment of Pfam domains}

Enrichment was computed with $\mathrm{R}$ function fisher.test (34) and Pfam domains (25) retrieved with recipe B4 of https://github.com/Ensembl/plant-scripts (35). Pfam domain counts for the complete proteome were used as expected frequencies. Only genes with an overlap $>50 \mathrm{bp}$ and domains with False Discovery Rate adjust values $(p<0.05)$ were considered.

\subsection{Control sets of annotated repeated sequences}

Repeated sequences annotated by sequencing consortia of olive tree (36), Rosa chinensis (37) and sunflower (38) were downloaded and formatted from

https://genomaolivar.dipujaen.es/db/downloads.php, https://iris.angers.inra.fr/obh/downloads and https://sunflowergenome.org/annotations-data. 


\section{Results and discussion}

\subsection{Construction and benchmark of a non-redundant library of repeats: nrTEplants}

A set of plant TE libraries and annotated repeats from selected species, listed on Table 1, plus cDNA sequence sets from the best annotated plant species in Ensembl, were curated and their TE classification terms uniformized. Then, they were merged and clustered $(95 \%$ identity, $75 \%$ coverage of shortest sequence). From the resulting 994,349 clusters, a total 174,426 clusters contained TE sequences and were 6-frame translated and assigned Pfam domains. Of these, a subset of 8,910 mixed clusters comprised both TE and cDNA sequences and required further processing (see example on Figure S1). After empirical assessment, we decided to take only clusters i) containing sequences from at least 6 different TE libraries (6 replicates), which eventually left out RosaTE repeats; and ii) with a fraction of sequences marked as 'Potential Host Gene' in RepetDB $<0.00$. The resulting nrTElibrary contains 171,104 sequences (see Tables S1 and S3).

In order to benchmark the newly constructed library we compiled a positive control, comprising 22 Pfam domains found in transposable elements, and a negative control, a list of 43 Pfam domains found in disease resistance NLR genes. With these controls, we estimated the sensitivity (0.909) and specificity (0.947). The nrTEplants library can be obtained at https://github.com/Ensembl/plant-scripts/releases/tag/v0.3 .

\subsection{Masking repeats within plant genomes}

A set of 20 plant genomes were selected from Ensembl (22) to benchmark repeat calling strategies. These are listed on Table 2 next to the genomic fraction of repeats reported in the literature and their GC content. All these genome sequences were annotated with RepeatMasker (7), nrTEplants and REdat (20), a repeat library used in Ensembl Plants. In addition, the fraction of repeats called by Red, based on K-mer enrichment, is also shown. Note that Red automatically selected k values from 13 to 16. 
On Figure 1 the resulting percentages of repeated sequences are plotted next to the values reported in the literature. The median difference between REdat repeated fraction and the literature reports is $26.5 \%$. This number is $9.8 \%$ for nrTEplants and $4.3 \%$ for Red. These results suggest that Red can successfully mask any genomes without previous knowledge of the repetitive sequence repertoire of a species. Moreover, repeats called by Red generally overlap sequences masked with REdat (66.6\%) and nrTEplants (73.8\%).

Table 3 summarizes the number of repeats, and their length, called by all tested strategies. We observe that Red calls more (a median of 845 per Mbp, compared to 391 for nrTEplants and 221 for REdat) but shorter repeats (median 143, compared to 284 and 217, respectively). Note that the numbers below are shown in the same REd, nrTEplants, REdat order for clarity.

Figure 2 summarizes how called repeats overlap with genes, exons and 500pb windows upstream and downstream genes. It can be seen that Red overlaps more with genes (median $17.8 \%$, compared to $13.7 \%$ and $5 \%$, respectively), but when exons are considered these numbers change to $9 \%, 15 \%$ and $4 \%$, respectively. The figure also shows that Red masks more proximal upstream and downstream space, which will likely have a positive impact on k-mer counting strategies for promoter analysis (39). The analysis on Table S4 shows that Red identifies four times more K-mers with 20+ copies in this regulatory space, which agrees with recent work that found that unidentified TEs are over-represented in specific regulatory networks (40).

In order to check whether the compared approaches masked preferentially genes from certain families, a Pfam enrichment analysis was carried out and summarized on Figure 3. It can be seen that Red repeats show the least enrichment. Furthermore, Red enriched Pfam domains are different across genomes with the exception of four domains found enriched in three genomes (reverse transcriptase-like, TIR, NB-ARC, and integrase core domains). In contrast, a few Pfam domains were enriched in 10+ genomes in genes overlapping repeats annotated with RM. The results on Table S5 show that nrTEplants performs better than REdat in this respect, with 87 domains compared to 153 (Red had 39 in total). 
As gene annotation is frequently performed after repeat masking, we reasoned this could affect the Pfam enrichment analyses. Therefore we carried out a complementary analysis where NLR genes were called de novo on the genomic sequences instead of using the Ensembl gene annotation. The results, summarized on Table S5, confirm that Red tends to mask less NLR genes than expected at genomic scale, with only one species (Trifolium pratense) with an odds ratio $>1$. In contrast, we obtained odd ratios greater than 1 for several species with REdat $(n=7)$ and nrTEplants $(n=12)$.

Overall, we observe that Red consistently produces repeated fractions similar to the expected values from the literature. The library nrTEplants also shows good performance in most species, but fails to recover the expected repeat fraction in cases such as melon or sunflower. Red also performs better than nrTEplants in terms of exon and upstream/downstream overlap. Furthermore, Red does not seem to systematically mask certain gene families. The lower values observed for REdat are a consequence of it underpredicting repeats, showing less sensitivity than the other approaches.

\subsection{Annotating Red-masked repeats within genomes with nrTEplants and minimap2}

In the previous analyses we showed that Red-base masking is an effective way of calling repeats in plant genomes. Moreover, we observed that nrTEplants behaves better than REdat in most cases. Therefore, we wanted to check whether repeats called with Red can be annotated and classified. For that, we aligned the repeat sequences against the non-redundant nrTElibrary with minimap2. The results are plotted on Figure 4, where it can be seen that, in most species, more than half of the repeat space can be annotated (median $65.9 \%$ ). As our library contains only transposable elements, we expected a fraction of unmapped space containing simple repeats or satellite DNA. However, as also observed on Figure 1, in a few species, only a small repeat fraction could be classified. We reasoned this was due to repeat consensus not represented in the library. This was confirmed in a separate experiment where olive and $R$. chinensis repeated sequences obtained from their 
authors were mapped to Red repeats, as seen in Figure 4 in a grey dashed line. A positive control was also carried out with sunflower repeated sequences, in order to confirm that no valuable repeats had been lost during the construction of nrTEplants.

These results were obtained with the default map-ont settings of minimap2. We also tried map-pab and asm20 settings, but obtained similar results. Red clover (Trifolium pratense) was re-analyzed replacing minimap2 with BLAST algorithms megablast, dc-megablast, blastn and rmblastn (41). Compared to the mapped fraction produced by minimap2 $(0.4 \%)$, a maximum value of $6.1 \%$ was obtained with blastn. This modest gain in sensitivity required 1,412 minutes. The algorithm rmblastn, used by RM, yielded a mapped fraction of $0.7 \%$. We concluded that the alternatives to minimap2 offered little gain at the cost of spiralling computing time.

Figure 5 shows the runtime and RAM required by the two-step protocol presented in this paper, measured on a CentOS7.9 computer using 4 cores of a Xeon E5-2620 v4 $(2.10 \mathrm{GHz})$ CPU. Panels A and B correspond to the first step, Red masking. It can be seen that all genomes tested take less than 40 min to run, with the exception of tetraploid Triticum turgidum, which took $71 \mathrm{~min}$. The memory consumption was below 20GB in all cases, but climbed to $22.7 \mathrm{~GB}$ and $29.9 \mathrm{~GB}$ in A. tauschii and T. turgidum. Panel C illustrates the runtime of the second step, the mapping of nrTEplants. It can be seen that all plants required less than $27 \mathrm{~min}$, except $A$. tauschii and T. turgidum, that took $3 \mathrm{~h}$ and $1 \mathrm{~h}$ respectively. The memory consumed by minimap2 was $3.8-4.0 \mathrm{~GB}$ in all cases. 


\section{Conclusions}

The hybrid, two-step methodology presented in this paper was tested on 20 angiosperms with genome sizes from 0.12 to $10.46 \mathrm{Gbp}$. Compared to RM, Red calls more and shorter repeats, and the obtained repeated genome fractions agree closely with those reported in the literature. Moreover, we find that Red k-mer masking does not have a preference for particular protein-coding families, in contrast to repeats annotated with RM using REdat and nrTEplants. Overall, more than half of Red masked sequences can be classified with nrTEplants, except in species with repeats not present in that library. Our protocol takes less than $2 \mathrm{~h}$ to run and up to $30 \mathrm{~GB}$ of RAM, and can use nrTEplants or any repeat library in FASTA format. 


\section{Acknowledgements}

We are grateful to Hani Girgis for his help with the Red source code and Doreen Ware for comments on drafts of this manuscript. We thank the Gramene team for continuous support and cooperation, as well as members of the Ensembl team for developing and maintaining the front-end and back-end software and infrastructure that underpins Ensembl Plants. 


\section{Funding}

The UK Biosciences and Biotechnology Research Council [BB/P016855/1, BB/P027849/1 and Ensembl-4-Breeders workshop support], the National Sciences Foundation [1127112], the ELIXIR implementation studies FONDUE and 'Apple as a Model for Genomic Information Exchange' and the European Molecular Biology Laboratory. Funding for open access charge: UK Biosciences and Biotechnology Research Council [BB/P016855/1]. Conflict of interest statement. Paul Flicek is a member of the Scientific Advisory Boards of Fabric Genomics, Inc. and Eagle Genomics, Ltd. 


\section{Figure captions}

Figure 1. Fraction of repeated sequences in plant genomes. Twenty genomes from release 49 (November 2020) of Ensembl Plants were annotated with RepeatMasker (7) and libraries REdat (20) and nrTEplants. The resulting percentage of repeated sequences is plotted next to the values reported in the literature for those genomes and the fraction of repeats provided by Repeat Detector (Red), based on K-mer enrichment (15). Species are sorted from small to large genome size.

$$
\text { " REdat }- \text { nrTEplants - literature }- \text { - Red }
$$

100

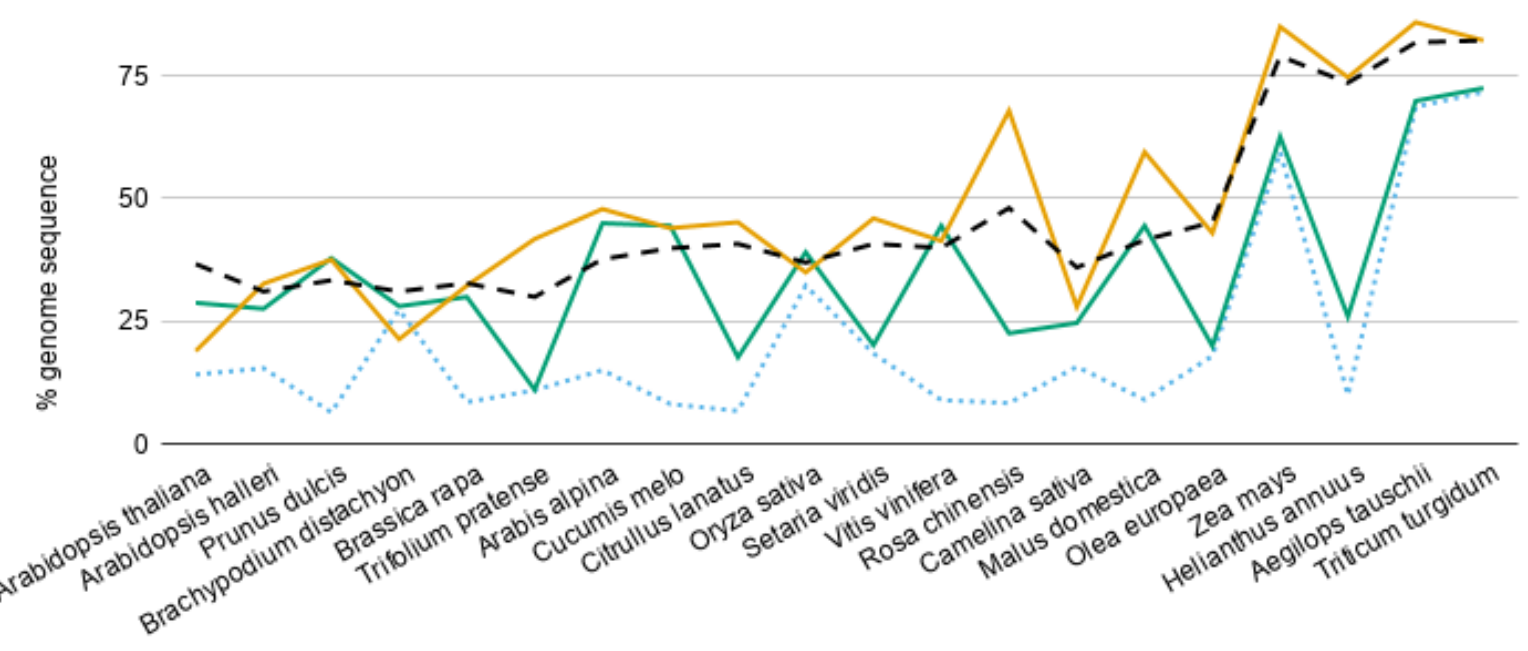


Figure 2. Fraction of exons, genes and 500bp up/downstream regions overlapping annotated repeats in plant genomes. Twenty genomes from release 49 (November 2020) of Ensembl Plants were annotated with Red (15) or RepeatMasker (7) with libraries REdat (20) and nrTEplants. The median genome space occupied by genes, exons and proximal upstream/downstream 500bp windows in these species are $126.7 \mathrm{Mbp}, 62.9 \mathrm{Mbp}$ and $37.7 \mathrm{Mbp}$, respectively. This plot was generated with $\mathrm{R}$ package vioplot (42).

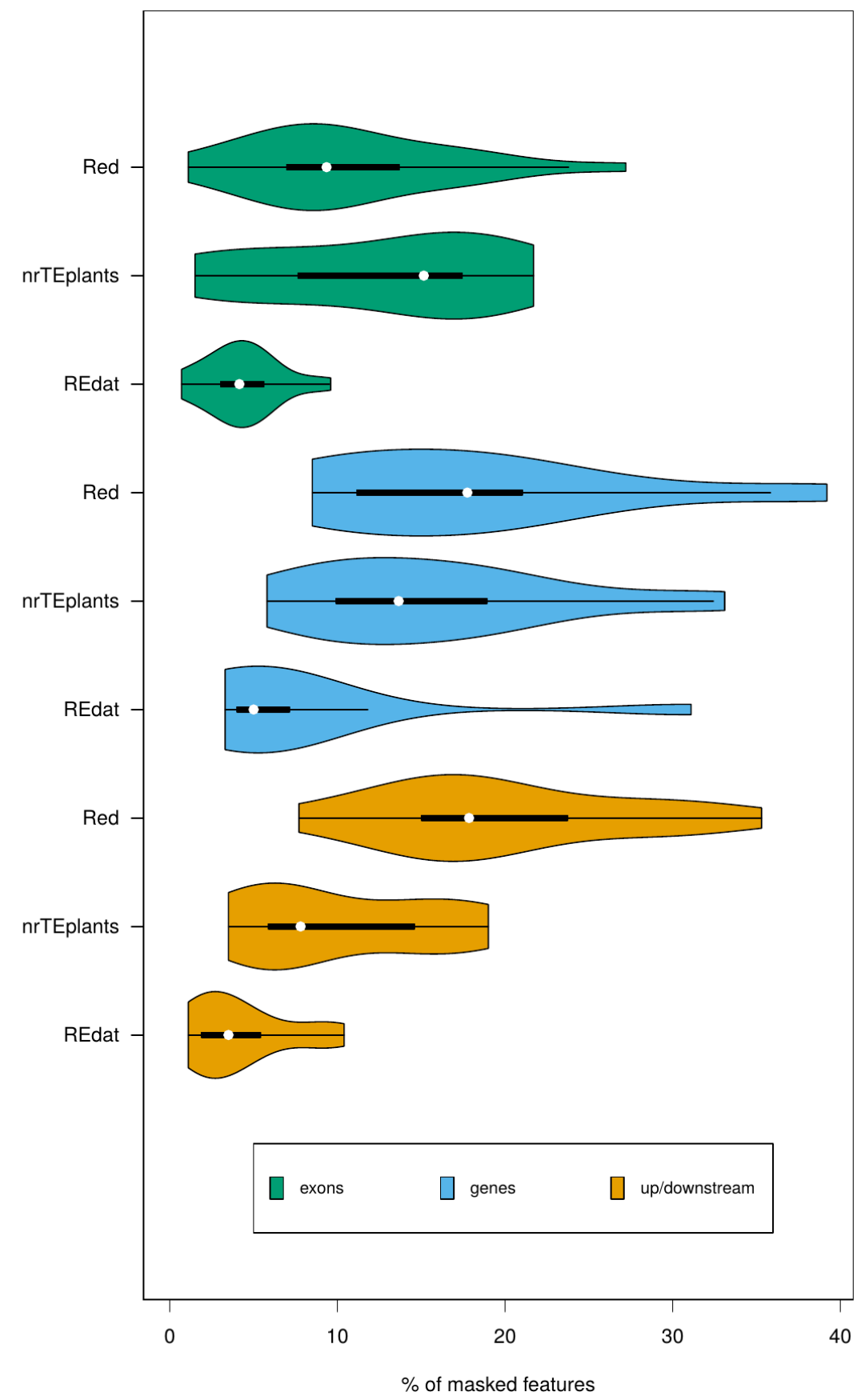


bioRxiv preprint doi: https://doi.org/10.1101/2021.03.22.436504; this version posted March 24,2021 . The copyright holder for this preprint (which was not certified by peer review) is the author/funder, who has granted bioRxiv a license to display the preprint in perpetuity. It is made available under aCC-BY 4.0 International license.

Figure 3. Enriched Pfam domains of protein-coding genes overlapping repeats. Twenty genomes from release 49 (November 2020) of Ensembl Plants were annotated with Repeat Detector (Red) (15) and RepeatMasker (7) with libraries REdat (20) and nrTEplants.

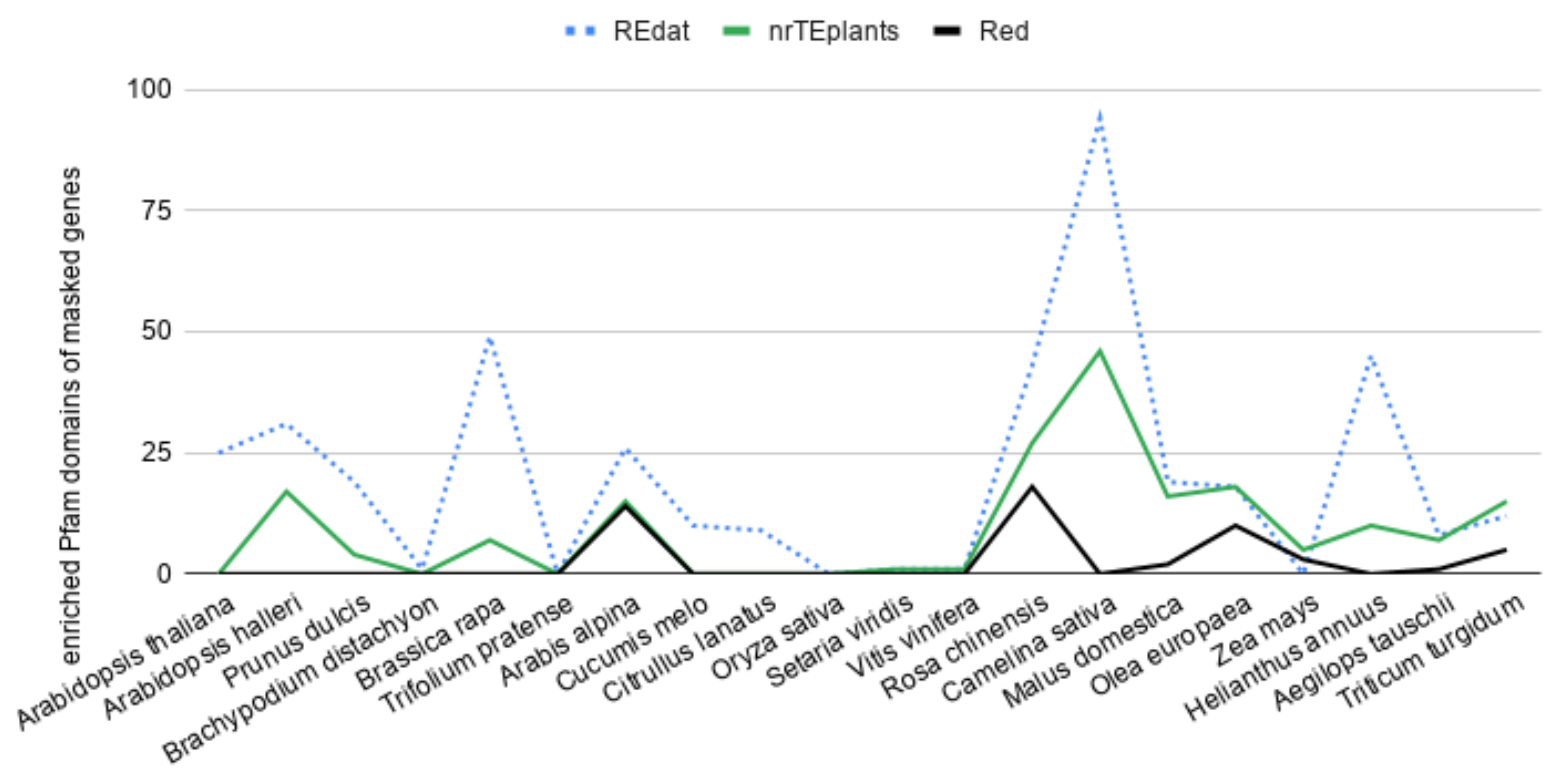


bioRxiv preprint doi: https://doi.org/10.1101/2021.03.22.436504; this version posted March 24,2021 . The copyright holder for this preprint (which was not certified by peer review) is the author/funder, who has granted bioRxiv a license to display the preprint in perpetuity. It is made available under aCC-BY 4.0 International license.

Figure 4. Fraction of Red repeats mapped to nrTEplants sequences. Twenty genomes from release 49 (November 2020) of Ensembl Plants were annotated with Repeat Detector (15). The resulting repeats were subsequently mapped to library nrTEplants with minimap2 (31), producing the genome fractions shown. Repeats from three species $(R$. chinensis, $O$. europaea and $H$. annuus) were also mapped to annotated repeats provided by the respective sequencing consortia as a control. Species are sorted from small to large genome size.

$$
\text { - \% Red repeats - \% annotated(nrTEplants) - - \% annotated(control) }
$$

$100.00 \%$

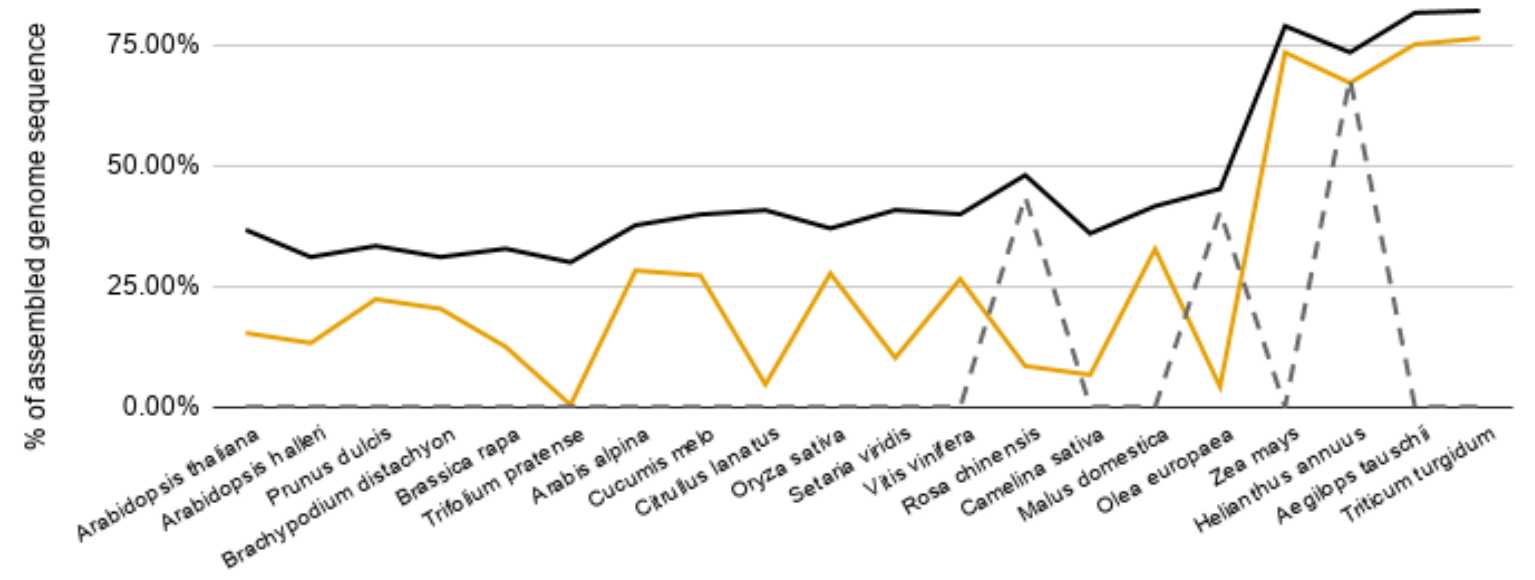


bioRxiv preprint doi: https://doi.org/10.1101/2021.03.22.436504; this version posted March 24,2021 . The copyright holder for this preprint (which was not certified by peer review) is the author/funder, who has granted bioRxiv a license to display the preprint in perpetuity. It is made available under aCC-BY 4.0 International license.

Figure 5. Runtime and memory requirements of a two-step repeat annotation protocol based on the Repeat Detector (15), minimap2 (31) and the nrTEplants library. The protocol was tested on twenty genomes from release 49 (November 2020) of Ensembl Plants. Similar values were measured on a Ubuntu box with four Core i5-6600 $(3.30 \mathrm{GHz}) \mathrm{CPU}$ cores.

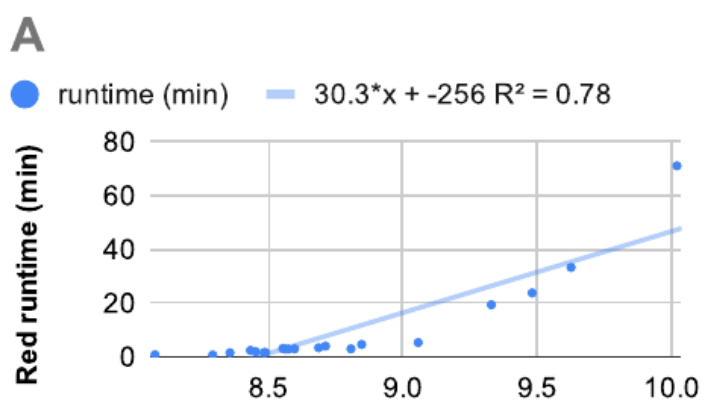

B

$\operatorname{RAM}(\mathrm{GB})=13.9^{\star} \mathrm{x}+-115 \mathrm{R}^{2}=0.794$

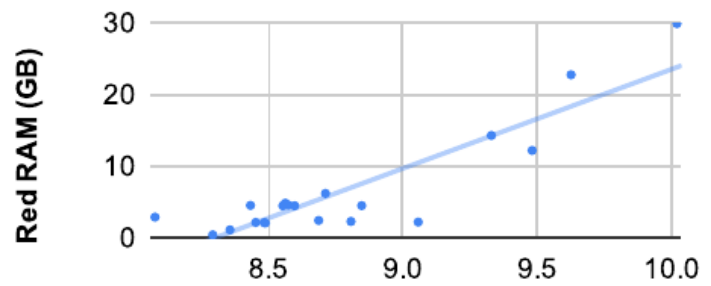

C

runtime $(\min )=56.8^{*} x+-479 R^{2}=0.401$

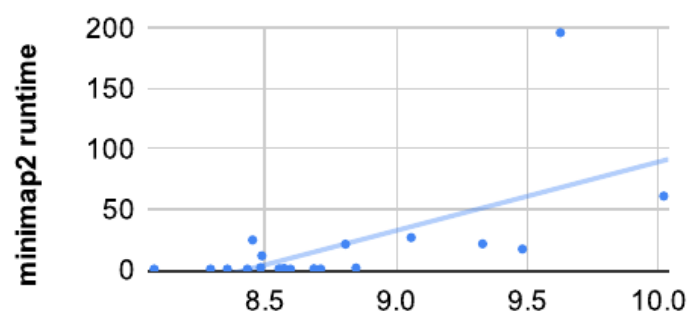

$\log 10$ genome size 
bioRxiv preprint doi: https://doi.org/10.1101/2021.03.22.436504; this version posted March 24, 2021. The copyright holder for this preprint (which was not certified by peer review) is the author/funder, who has granted bioRxiv a license to display the preprint in perpetuity. It is made available under aCC-BY 4.0 International license.

\section{Supplementary Figures}

Figure S1. Cluster with two Arabidopsis thaliana cDNA sequences (AT4G16920.2 and AT4G16950.1) and transposable element TEdenovo-B-R2288-Map4 from library repetDB. These sequences contain Pfam domain NB-ARC (PF00931), which is part of NLR defense proteins. Figure generated with Bioedit (43) from cluster 269_AT4G16920.2.

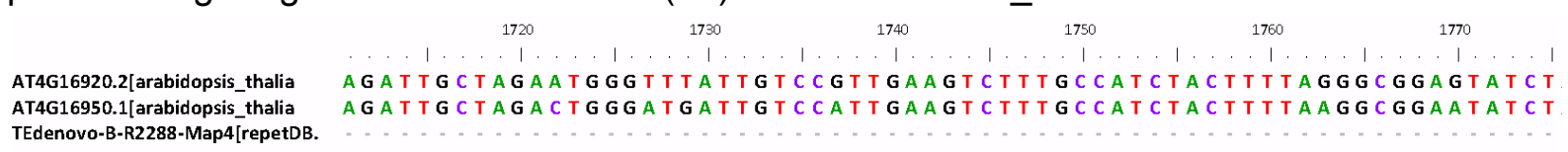

TEdenovo-B-R2288-Map4[repetDB.

1810

1820

1830

1840

1850

1860

AT4G16920.2[arabidopsis_thalia AT4G16950.1[arabidopsis_thalia AAGCTTGAGAAACTGTGGGAAGGAACTCTGCCCCTTGGAAGTCTCAAGAAGATGAATTTGTGTA TEdenovo-B-R2288-Map4[repetDB.

AT4G16920.2[arabidopsis_thalia
AT4G16950.1[arabidopsis_thalia
TEdenovo-B-R2288-Map4[repetDB.

AT4G16920.2[arabidopsis_thalia AT4G16950.1[arabidopsis_thalia TEdenovo-B-R2288-Map4[repetDB.

AT4G16920.2[arabidopsis_thalia AAGCTTGAGAAACG GCCCCTTGGAAGTCTCAAGAAGATGAATTTGTGGTG

AT4G16950.1[arabidopsis_thalia

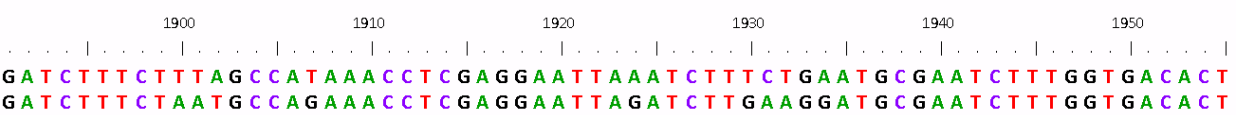

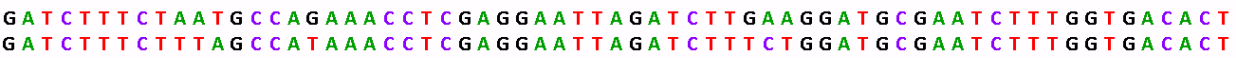

1990

2010

2020

2030

2040

AAACTGAGGACG AAACTGAGGAAGTTACATTGTTCGGGGGTGATATTAATAGATTTAAAATCATTAGAAGGCATGTG AAACTGAGGACGTTATATTGTTCGGGGGTCTATTAATAGATTTAAAATCATTAGAAGGATG 


\section{Tables}

Table 1. Collections of plant repeated sequences used as components of nrTEplants.

\begin{tabular}{|c|c|c|c|c|}
\hline Dataset & Description / URL & $\begin{array}{c}\text { Last } \\
\text { updated }\end{array}$ & $\begin{array}{l}\text { Total } \\
\text { sequen } \\
\text { ces }\end{array}$ & $\begin{array}{l}\text { Median } \\
\text { length } \\
\text { (bp) }\end{array}$ \\
\hline TREP & $\begin{array}{l}\text { TEs from Triticeae and various other species. } \\
\text { http://botserv2.uzh.ch/kelldata/trep-db }\end{array}$ & 2019 & 4162 & 4234 \\
\hline SINEbase & $\begin{array}{c}\text { Consensus sequences of SINE families (44). } \\
\text { http://sines.eimb.ru }\end{array}$ & 2020 & 60 & 183 \\
\hline REdat & $\begin{array}{l}\text { Repeat sequences from several sources and the } \\
\text { species in PGSB PlantsDB (20). } \\
\text { https://pgsb.helmholtz-muenchen.de/plant/recat }\end{array}$ & 2013 & 61730 & 7504 \\
\hline RepetDB & $\begin{array}{c}\text { Repeats detected and classified by TEdenovo and } \\
\text { used by TEannot (9). } \\
\text { http://urgi.versailles.inra.fr/repetdb }\end{array}$ & 2019 & 33416 & 3567 \\
\hline EDTArice & $\begin{array}{l}\text { Extensive de-novo TE Annotator (45). } \\
\text { https://github.com/oushujun/EDTA }\end{array}$ & 2019 & 2431 & 984 \\
\hline EDTAmaize & $\begin{array}{l}\text { Extensive de-novo TE Annotator (45) } \\
\text { https://github.com/oushujun/EDTA }\end{array}$ & 2019 & 1362 & 3308 \\
\hline SoyBaseTE & $\begin{array}{c}\text { Comprehensive database of soybean TEs (46). } \\
\text { https://www.soybase.org/soytedb }\end{array}$ & 2010 & 38664 & 1716 \\
\hline TAIR10TE & $\begin{array}{l}\text { Arabidopsis thaliana TEs } \\
\text { https://www.arabidopsis.org }\end{array}$ & 2019 & 31189 & 305 \\
\hline SunflowerTE & (47) https://www.sunflowergenome.org & 2016 & 73627 & 4709 \\
\hline SUNREP & $\begin{array}{l}\text { The repetitive component of the sunflower } \\
\text { genome (48) } \\
\text { pgagl.agr.unipi.it/sequence-repository }\end{array}$ & 2013 & 47441 & 616 \\
\hline MelonTE & Personal communication (49) & 2020 & 1560 & 3981 \\
\hline RosaTE & (37) https://iris.angers.inra.fr/obh/downloads & 2017 & 355304 & 226 \\
\hline
\end{tabular}


Table 2. Plant genomes from release 49 (September 2020) of Ensembl Plants (22) used in this work and their reported repeated fractions in the literature.

\begin{tabular}{|c|c|c|c|}
\hline Species & $\%$ GC & $\begin{array}{l}\text { Assembled } \\
\text { genome size } \\
\text { (Mbp) }\end{array}$ & $\begin{array}{l}\text { Reported \% } \\
\text { repeated fraction } \\
\text { (source) }\end{array}$ \\
\hline Arabidopsis thaliana & 36.1 & 119.7 & $19.0(50)$ \\
\hline Arabidopsis halleri & 36.0 & 196.2 & $32.7(50)$ \\
\hline Prunus dulcis & 37.6 & 227.5 & $37.6(51)$ \\
\hline Brachypodium distachyon & 46.4 & 271.2 & $21.4(52)$ \\
\hline Brassica rapa & 35.3 & 283.8 & $32.3(53)$ \\
\hline Trifolium pratense & 32.4 & 304.8 & $41.8(54)$ \\
\hline Arabis alpina & 36.8 & 308.0 & $47.9(55)$ \\
\hline Cucumis melo & 33.5 & 357.9 & $44.0(56)$ \\
\hline Citrullus lanatus & 33.6 & 365.5 & $45.2(57)$ \\
\hline Oryza sativa & 43.6 & 375.0 & $35(58)$ \\
\hline Setaria viridis & 46.2 & 395.7 & $46(59)$ \\
\hline Vitis vinifera & 34.5 & 486.3 & $41.4(60)$ \\
\hline Rosa chinensis & 38.8 & 515.6 & $67.9(61)$ \\
\hline Camelina sativa & 36.6 & 641.4 & $28(62)$ \\
\hline Malus domestica & 38.0 & 702.9 & $59.5(63)$ \\
\hline Olea europaea & 35.4 & 1140.9 & $43(64)$ \\
\hline Zea mays & 46.9 & 2135.1 & $85(65)$ \\
\hline Helianthus annuus & 38.5 & 3027.8 & $74.7(38)$ \\
\hline Aegilops tauschii & 46.3 & 4224.9 & $85.9(66)$ \\
\hline Triticum turgidum & 46.0 & 10463.1 & $82.2(67)$ \\
\hline
\end{tabular}


Table 3. Summary of repeated sequences annotated with Red (15) and RepeatMasker (7) with libraries nrTEplants and REdat (20). Repeats per Mbp (r/Mbp) and median length (len) are shown.

\begin{tabular}{|l|r|r|r|r|r|r|}
\hline \multicolumn{1}{|c|}{ Species } & \multicolumn{2}{|c|}{ Red } & \multicolumn{2}{c|}{ nrTEplants } & \multicolumn{2}{c|}{ REdat } \\
\hline Arabidopsis thaliana & 357 & 404 & 184 & 1173 & 201 & 963 \\
\hline Arabidopsis halleri & 1152 & 124 & 417 & 308 & 295 & 209 \\
\hline Prunus dulcis & 1445 & 123 & 402 & 267 & 241 & 181 \\
\hline Brachypodium & & & & & & \\
distachyon & 906 & 169 & 474 & 415 & 318 & 222 \\
\hline Brassica rapa & 554 & 121 & 274 & 193 & 249 & 183 \\
\hline Trifolium pratense & 1227 & 110 & 564 & 259 & 244 & 163 \\
\hline Arabis alpina & 1106 & 122 & 417 & 281 & 313 & 223 \\
\hline Cucumis melo & 886 & 112 & 416 & 190 & 145 & 183 \\
\hline Citrullus lanatus & 853 & 118 & 416 & 329 & 145 & 213 \\
\hline Oryza sativa & 788 & 198 & 118 & 388 & 158 & 352 \\
\hline Setaria viridis & 756 & 148 & 301 & 478 & 180 & 201 \\
\hline Vitis vinifera & 790 & 139 & 255 & 254 & 329 & 238 \\
\hline Rosa chinensis & 742 & 147 & 428 & 255 & 344 & 239 \\
\hline Camelina sativa & 837 & 109 & 464 & 287 & 162 & 148 \\
\hline Malus domestica & 900 & 150 & 367 & 268 & 182 & 207 \\
\hline Olea europaea & 626 & 165 & 294 & 271 & 266 & 274 \\
\hline Zea mays & 911 & 206 & 457 & 153 & 511 & 147 \\
\hline Helianthus annuus & 410 & 312 & 183 & 1270 & 171 & 1456 \\
\hline Aegilops tauschii & 872 & 132 & 381 & 395 & 143 & 247 \\
\hline Triticum turgidum & 397 & 211 & 171 & 696 & 174 & 669 \\
\hline
\end{tabular}


bioRxiv preprint doi: https://doi.org/10.1101/2021.03.22.436504; this version posted March 24,2021 . The copyright holder for this preprint (which was not certified by peer review) is the author/funder, who has granted bioRxiv a license to display the preprint in perpetuity. It is made available under aCC-BY 4.0 International license.

\section{Supplementary Tables}

Table S1. Contribution of individual datasets to the nrTEplants library of repeats (v0.3).

\begin{tabular}{|l|l|}
\hline Dataset & \# of sequences \\
\hline SunflowerTE & 58071 \\
\hline REdat & 39509 \\
\hline repetDB & 26006 \\
\hline SoyBaseTE & 21766 \\
\hline TAIR10TE & 21056 \\
\hline EDTArice & 1844 \\
\hline MelonTE & 1171 \\
\hline EDTAmaize & 805 \\
\hline TREP & 789 \\
\hline SINEbase & 44 \\
\hline SUNREP & 43 \\
\hline
\end{tabular}


Table S2. Enriched Pfam domains of protein-coding genes overlapping repeats called with Red (15) and RepeatMasker (7) with libraries nrTEplants and REdat (20). Only domains found enriched in at least three species are shown. Domains in bold are shared by all repeat-calling strategies and correspond to Integrase core domains (PF00665), NB-ARC (PF00931), Reverse transcriptase-like (PF13456) and TIR (PF01582).

\begin{tabular}{|l|r|l|r|l|r|}
\hline \multicolumn{2}{|c|}{ REdat } & \multicolumn{2}{c|}{ nrTEplants } & \multicolumn{2}{c|}{ Red } \\
\hline Pfam domain & count & Pfam domain & count & Pfam domain & count \\
\hline PF00069 & 13 & PF00931 & 11 & PF13456 & 3 \\
\hline PF07714 & 10 & PF07727 & 6 & PF01582 & 3 \\
\hline PF00005 & 10 & PF07714 & 6 & PF00931 & 3 \\
\hline PF01095 & 9 & PF01582 & 6 & PF00665 & 3 \\
\hline PF13947 & 8 & PF00078 & 6 & & \\
\hline PF07727 & 8 & PF00069 & 6 & & \\
\hline PF00931 & 8 & PF18052 & 5 & & \\
\hline PF13855 & 7 & PF14223 & 5 & & \\
\hline PF01453 & 7 & PF07725 & 5 & & \\
\hline PF00847 & 7 & PF00665 & 5 & & \\
\hline PF00665 & 7 & PF17921 & 4 & & \\
\hline PF00078 & 7 & PF13976 & 4 & & \\
\hline PF14510 & 6 & PF13855 & 4 & & \\
\hline PF14432 & 6 & PF03732 & 4 & & \\
\hline PF14223 & 6 & PF00560 & 4 & & \\
\hline PF08370 & 6 & PF14111 & 3 & & \\
\hline PF08276 & 6 & PF13947 & 3 & & \\
\hline PF01582 & 6 & PF13456 & 3 & & \\
\hline PF00954 & 6 & PF08276 & 3 & & \\
\hline PF00067 & 6 & PF08263 & 3 & & \\
\hline PF17921 & 5 & PF01453 & 3 & & \\
\hline PF17919 & 5 & PF00954 & 3 & & \\
\hline PF17917 & 5 & PF00122 & 3 & & \\
\hline PF13976 & 5 & PF00005 & 3 & & \\
\hline PF11721 & 5 & & & & \\
\hline PF08387 & 5 & & & & \\
\hline PF08284 & 5 & & & \\
\hline PF08263 & 5 & & & \\
\hline PF07725 & 5 & & & \\
\hline PF07723 & 5 & & & \\
\hline
\end{tabular}


bioRxiv preprint doi: https://doi.org/10.1101/2021.03.22.436504; this version posted March 24,2021 . The copyright holder for this preprint (which was not certified by peer review) is the author/funder, who has granted bioRxiv a license to display the preprint in perpetuity. It is made available under aCC-BY 4.0 International license.

\begin{tabular}{|l|r|l|l|l|l|}
\hline PF03732 & 5 & & & & \\
\hline PF00560 & 5 & 5 & & & \\
\hline PF00082 & 4 & & & & \\
\hline PF19055 & 4 & & & & \\
\hline PF17766 & 4 & & & & \\
\hline PF08246 & 4 & & & & \\
\hline PF02365 & 4 & & & & \\
\hline PF01061 & 4 & & & & \\
\hline PF00664 & 4 & & & & \\
\hline PF00201 & 4 & & & & \\
\hline PF00112 & 3 & & & \\
\hline PF00098 & 3 & & & & \\
\hline PF00012 & 3 & & & & \\
\hline PF14380 & 3 & & & & \\
\hline PF13456 & 3 & & & & \\
\hline PF12819 & 3 & & & \\
\hline PF08372 & 3 & & & \\
\hline PF08031 & 3 & & & \\
\hline PF05922 & 3 & & & \\
\hline PF00450 & & & \\
\hline PF00305 & 3 & & & \\
\hline PF00249 & 3 & & \\
\hline PF00223 & & & & \\
\hline
\end{tabular}


Table S3. Summary of classified repeats in the nrTEplants library.

\begin{tabular}{|c|c|}
\hline Superfamily/family & count \\
\hline LTR/Gypsy & 45394 \\
\hline LTR/Copia & 26009 \\
\hline LTR & 24532 \\
\hline TIR & 18590 \\
\hline RC/Helitron & 9080 \\
\hline TRIM & 6573 \\
\hline Helitron & 4384 \\
\hline MobileElement & 4020 \\
\hline DNA/MuDR & 3900 \\
\hline TIR/Tc1-Mariner & 3404 \\
\hline LINE & 3342 \\
\hline Unclassified & 3061 \\
\hline TIR/Mutator & 2287 \\
\hline DNA & 1810 \\
\hline TIR/PIF-Harbinge & 1367 \\
\hline DNA/En-Spm & 1088 \\
\hline LINE/L1 & 1076 \\
\hline Mutator & 820 \\
\hline SINE & 785 \\
\hline DNA/HAT & 751 \\
\hline DIRS & 707 \\
\hline MITE & 663 \\
\hline rRNA & 565 \\
\hline DNA/Harbinger & 516 \\
\hline Other & 416 \\
\hline DNA/Mite & 397 \\
\hline Retroelement & 389 \\
\hline DNA/hAT & 300 \\
\hline TIR/hAT & 299 \\
\hline LARD & 299 \\
\hline
\end{tabular}


bioRxiv preprint doi: https://doi.org/10.1101/2021.03.22.436504; this version posted March 24,2021 . The copyright holder for this preprint (which was not certified by peer review) is the author/funder, who has granted bioRxiv a license to display the preprint in perpetuity. It is made available under aCC-BY 4.0 International license.

\begin{tabular}{|c|c|}
\hline DNAnona/Helitron & 260 \\
\hline DNAnona/MULE & 251 \\
\hline DNA/Pogo & 245 \\
\hline DNA/TcMar & 233 \\
\hline DNAnona/hAT & 202 \\
\hline Other/Simple & 184 \\
\hline TIR/PIF-Harbinger & 176 \\
\hline nonLTR & 172 \\
\hline DNA/Stowaway & 161 \\
\hline RathE1_cons & 156 \\
\hline Satellite & 155 \\
\hline non & 130 \\
\hline hAT & 129 \\
\hline DNA/Mariner & 126 \\
\hline DNA/Mutator & 122 \\
\hline MITE/Tourist & 112 \\
\hline TIR/CACTA & 105 \\
\hline DNAnona/MULEtir & 92 \\
\hline RathE3_cons & 87 \\
\hline DNA/Tc1 & 86 \\
\hline TIR/Mariner & 81 \\
\hline DNAnona/CACTA & 74 \\
\hline DNAauto/MULE & 72 \\
\hline LINE? & 68 \\
\hline TIR/Harbinger & 62 \\
\hline RathE2_cons & 50 \\
\hline Helitron/Helitron & 45 \\
\hline non-LTR(SINE) & 43 \\
\hline DNA/CACTA & 37 \\
\hline DNA/Tc1-Mariner & 35 \\
\hline MITE/Stow & 35 \\
\hline DNA/Tourist & 32 \\
\hline
\end{tabular}


bioRxiv preprint doi: https://doi.org/10.1101/2021.03.22.436504; this version posted March 24,2021 . The copyright holder for this preprint (which was not certified by peer review) is the author/funder, who has granted bioRxiv a license to display the preprint in perpetuity. It is made available under aCC-BY 4.0 International license.

\begin{tabular}{|c|c|}
\hline non-LTR(SINE)/I & 32 \\
\hline Maverick & 31 \\
\hline DNAnona/Tourist & 29 \\
\hline LTR/TRIM & 26 \\
\hline DNAnona/PILE & 26 \\
\hline TIR/EnSpm/CACTA & 25 \\
\hline LARD|TRIM & 24 \\
\hline DNAauto/hAT & 22 \\
\hline DNAauto/Helitron & 17 \\
\hline DNAauto/CACTA & 17 \\
\hline LINE/Ukn & 15 \\
\hline DNAauto/MLE & 14 \\
\hline DNAnona/POLE & 14 \\
\hline DNAauto/POLE & 12 \\
\hline SINE|TRIM & 10 \\
\hline DNAnona/CACTG & $10 f$ \\
\hline non-LTR(SINE)/Jokey & 10 \\
\hline LTR $\mid$ TIR & 10 \\
\hline DNAnona/MLE & 8 \\
\hline DIRS|TIR & 8 \\
\hline DNAauto/PILE & 8 \\
\hline non-LTR(SINE)/Pan & 8 \\
\hline DNA/hAT-Ac & 8 \\
\hline TIR/PONG & 8 \\
\hline non-LTR(SINE)/L1 & 8 \\
\hline Helitron|LARD & 7 \\
\hline LTR/Echo & 5 \\
\hline PLE & 5 \\
\hline LTR/Halcyon & 5 \\
\hline Other/Centromeric & 4 \\
\hline
\end{tabular}


bioRxiv preprint doi: https://doi.org/10.1101/2021.03.22.436504; this version posted March 24,2021 . The copyright holder for this preprint (which was not certified by peer review) is the author/funder, who has granted bioRxiv a license to display the preprint in perpetuity. It is made available under aCC-BY 4.0 International license.

\begin{tabular}{|l|r|}
\hline Helitron/TRIM & 3 \\
\hline LTR/Solo & 3 \\
\hline DNA/Helitron & 3 \\
\hline LTR/DIRS & 3 \\
\hline DNAnona & 3 \\
\hline Crypton & 2 \\
\hline SINE/LARD & 2 \\
\hline Evirus/ERTBV & 2 \\
\hline TIR/PiggyBac & 2 \\
\hline TIR/Maverick & 2 \\
\hline DNAauto/CACTG & 2 \\
\hline subtelomere/4-12-1 & 1 \\
\hline Satellite/rice & 1 \\
\hline TIR/P & 1 \\
\hline Evirus/ERTBV-A & 1 \\
\hline Centro/tandem & 1 \\
\hline non-LTR(SINE)/R2 & 1 \\
\hline DNAtransposon & 1 \\
\hline non-LTR(SINE)/Chronos & 1 \\
\hline knob/TR-1 & 1 \\
\hline
\end{tabular}


Table S4. Median number of repeat K-mers with 20+ copies overlapping 500bp up/downstream regions in plant genomes. Values were computed from twenty genomes from release 49 (November 2020) of Ensembl Plants annotated with Red (15) or RepeatMasker (7) with libraries REdat (20) and nrTEplants. Total k-mers are also shown.

\begin{tabular}{|l|r|r|r|l|l|l|}
\hline$K$ & $\begin{array}{c}\text { REdat } \\
(\mathbf{n}>\mathbf{2 0})\end{array}$ & $\begin{array}{c}\text { nrTEplants } \\
(\mathbf{n}>\mathbf{2 0})\end{array}$ & $\begin{array}{c}\text { Red } \\
(\mathbf{n}>\mathbf{2 0})\end{array}$ & $\begin{array}{c}\text { REdat } \\
\text { (total) }\end{array}$ & $\begin{array}{c}\text { nrTEplants } \\
\text { (total) }\end{array}$ & $\begin{array}{c}\text { Red } \\
(\text { total })\end{array}$ \\
\hline 16 & 2101 & 3806.5 & 14730 & 1212499.5 & 3230821 & 6125298 \\
\hline 21 & 1307.5 & 2285.5 & 8057 & 1178632.5 & 3150425.5 & 5925111.5 \\
\hline 31 & 606.5 & 984 & 4256.5 & 1112352.5 & 2993877.5 & 5533979 \\
\hline
\end{tabular}


Table S5. Odd ratios of NLR masking for genes overlapping > 50bp of masked sequences. Values were computed from twenty genomes from release 49 (November 2020) of Ensembl Plants annotated with Red (15) or RepeatMasker (7) with libraries REdat (20) and nrTEplants.

\begin{tabular}{|l|r|r|r|r|r|}
\hline \multicolumn{1}{|c|}{ Species } & $\begin{array}{c}\text { NLR } \\
\text { genes }\end{array}$ & $\begin{array}{c}\text { NLR } \\
\text { space } \\
\text { (bp) }\end{array}$ & REdat & nrTEplants & \multicolumn{1}{c|}{ Red } \\
\hline Arabidopsis thaliana & 69 & 201660 & 0.77 & 2.6 & 0.71 \\
\hline Arabidopsis halleri & 209 & 635687 & 0.56 & 2.41 & 0.62 \\
\hline Prunus dulcis & 387 & 1354547 & 2.52 & 2.05 & 0.97 \\
\hline Brachypodium distachyon & 344 & 1249602 & 0.46 & 0.59 & 0.46 \\
\hline Brassica rapa & 219 & 729119 & 0.89 & 2.22 & 0.66 \\
\hline Trifolium pratense & 553 & 1781566 & 2.65 & 4.11 & 1.06 \\
\hline Arabis alpina & 364 & 1201405 & 0.51 & 1.46 & 0.44 \\
\hline Cucumis melo & 89 & 294239 & 1.59 & 1.46 & 0.37 \\
\hline Citrullus lanatus & 43 & 164993 & 1.33 & 2.44 & 0.22 \\
\hline Oryza sativa & 45 & 169051 & 0.22 & 0.44 & 0.22 \\
\hline Setaria viridis & 453 & 1682607 & 0.35 & 0.47 & 0.56 \\
\hline Vitis vinifera & 739 & 2723777 & 1.54 & 1.36 & 0.98 \\
\hline Rosa chinensis & 963 & 3347977 & 1.42 & 2.97 & 0.8 \\
\hline Camelina sativa & 573 & 1808571 & 0.39 & 2.3 & 0.53 \\
\hline Malus domestica & 637 & 2535932 & 1.5 & 1.63 & 0.89 \\
\hline Olea europaea & 402 & 1095646 & 0.42 & 0.73 & 0.21 \\
\hline Zea mays & 158 & 487237 & 0 & 0 & 0.43 \\
\hline Helianthus annuus & 604 & 2055877 & 0.29 & 0.88 & 0.59 \\
\hline Aegilops tauschii & 3144217 & 0 & 0.14 & 0.14 \\
\hline Triticum turgidum & 8351371 & 0 & 0.13 & 0.13 \\
\hline
\end{tabular}


Bibliography

1. Novák P, Guignard MS, Neumann P, Kelly LJ, Mlinarec J, Koblížková A, et al. Repeat-sequence turnover shifts fundamentally in species with large genomes. Nat Plants. 2020 Oct 19;6(11):1325-9.

2. MCCLINTOCK B. The origin and behavior of mutable loci in maize. Proc Natl Acad Sci USA. 1950 Jun;36(6):344-55.

3. Studer A, Zhao Q, Ross-Ibarra J, Doebley J. Identification of a functional transposon insertion in the maize domestication gene tb1. Nat Genet. 2011 Sep 25;43(11):1160-3.

4. Thieme M, Lanciano S, Balzergue S, Daccord N, Mirouze M, Bucher E. Inhibition of RNA polymerase II allows controlled mobilisation of retrotransposons for plant breeding. Genome Biol. 2017 Jul 7;18(1):134.

5. Gordon SP, Contreras-Moreira B, Woods DP, Des Marais DL, Burgess D, Shu S, et al. Extensive gene content variation in the Brachypodium distachyon pan-genome correlates with population structure. Nat Commun. 2017 Dec 19;8(1):2184.

6. Wicker T, Sabot F, Hua-Van A, Bennetzen JL, Capy P, Chalhoub B, et al. A unified classification system for eukaryotic transposable elements. Nat Rev Genet. 2007 Dec;8(12):973-82.

7. Smit AFA, Hubler R, Green P. RepeatMasker Open-4.0. 2015.

8. Bao W, Kojima KK, Kohany O. Repbase Update, a database of repetitive elements in eukaryotic genomes. Mob DNA. 2015 Jun 2;6:11.

9. Amselem J, Cornut G, Choisne N, Alaux M, Alfama-Depauw F, Jamilloux V, et al. RepetDB: a unified resource for transposable element references. Mob DNA. 2019 Jan 29;10:6.

10. Lerat $\mathrm{E}$. Identifying repeats and transposable elements in sequenced genomes: how to find your way through the dense forest of programs. Heredity. 2010 Jun;104(6):520-33.

11. Bayer PE, Edwards D, Batley J. Bias in resistance gene prediction due to repeat masking. Nat Plants. 2018 Oct 1;4(10):762-5.

12. Wierzbicki F, Schwarz F, Cannalonga O, Kofler R. Generating high quality assemblies for genomic analysis of transposable elements. BioRxiv. 2020 Mar 28;

13. Van Bel M, Bucchini F, Vandepoele K. Gene space completeness in complex plant genomes. Curr Opin Plant Biol. 2019 Feb 21;48:9-17.

14. Hickey G, Heller D, Monlong J, Sibbesen JA, Sirén J, Eizenga J, et al. Genotyping structural variants in pangenome graphs using the vg toolkit. Genome Biol. $2020 \mathrm{Feb}$ 12;21(1):35.

15. Girgis HZ. Red: an intelligent, rapid, accurate tool for detecting repeats de-novo on the genomic scale. BMC Bioinformatics. 2015 Jul 24;16:227.

16. Kurtz S, Narechania A, Stein JC, Ware D. A new method to compute K-mer frequencies and its application to annotate large repetitive plant genomes. BMC Genomics. 2008 Oct 31;9:517.

17. Beier S, Ulpinnis C, Schwalbe M, Münch T, Hoffie R, Koeppel I, et al. Kmasker plants - 
a tool for assessing complex sequence space in plant species. Plant J. 2020 Jan 11;102(3):631-42.

18. da Cruz MHP, Domingues DS, Saito PTM, Paschoal AR, Bugatti PH. TERL: classification of transposable elements by convolutional neural networks. Brief Bioinformatics. 2020 Sep 8;

19. Harris RS. Improved pairwise alignment of genomic DNA [Doctoral dissertation]. The Pennsylvania State University; 2007.

20. Nussbaumer T, Martis MM, Roessner SK, Pfeifer M, Bader KC, Sharma S, et al. MIPS PlantsDB: a database framework for comparative plant genome research. Nucleic Acids Res. 2013 Jan;41(Database issue):D1144-51.

21. Wilkinson MD, Dumontier M, Aalbersberg IJJ, Appleton G, Axton M, Baak A, et al. The FAIR Guiding Principles for scientific data management and stewardship. Sci Data. 2016 Mar 15;3:160018.

22. Howe KL, Contreras-Moreira B, De Silva N, Maslen G, Akanni W, Allen J, et al. Ensembl Genomes 2020-enabling non-vertebrate genomic research. Nucleic Acids Res. 2020 Jan 8;48(D1):D689-95.

23. UniProt Consortium. UniProt: a worldwide hub of protein knowledge. Nucleic Acids Res. 2019 Jan 8;47(D1):D506-15.

24. Contreras-Moreira B, Cantalapiedra CP, García-Pereira MJ, Gordon SP, Vogel JP, Igartua $\mathrm{E}$, et al. Analysis of Plant Pan-Genomes and Transcriptomes with GET_HOMOLOGUES-EST, a Clustering Solution for Sequences of the Same Species. Front Plant Sci. 2017 Feb 14;8:184.

25. Mistry J, Chuguransky S, Williams L, Qureshi M, Salazar GA, Sonnhammer ELL, et al. Pfam: The protein families database in 2021. Nucleic Acids Res. 2021 Jan 8;49(D1):D412-9.

26. Osuna-Cruz CM, Paytuvi-Gallart A, Di Donato A, Sundesha V, Andolfo G, Aiese Cigliano R, et al. PRGdb 3.0: a comprehensive platform for prediction and analysis of plant disease resistance genes. Nucleic Acids Res. 2018 Jan 4;46(D1):D1197-201.

27. Eddy SR. Profile hidden Markov models. Bioinformatics. 1998;14(9):755-63.

28. Kinsella RJ, Kähäri A, Haider S, Zamora J, Proctor G, Spudich G, et al. Ensembl BioMarts: a hub for data retrieval across taxonomic space. Database (Oxford). 2011 Jul 23;2011:bar030.

29. Steuernagel B, Witek K, Krattinger SG, Ramirez-Gonzalez RH, Schoonbeek H-J, Yu $G$, et al. The NLR-Annotator Tool Enables Annotation of the Intracellular Immune Receptor Repertoire. Plant Physiol. 2020 Mar 17;183(2):468-82.

30. Stabenau A, McVicker G, Melsopp C, Proctor G, Clamp M, Birney E. The Ensembl core software libraries. Genome Res. 2004 May;14(5):929-33.

31. Li H. Minimap2: pairwise alignment for nucleotide sequences. Bioinformatics. 2018 Sep 15;34(18):3094-100.

32. Quinlan AR, Hall IM. BEDTools: a flexible suite of utilities for comparing genomic features. Bioinformatics. 2010 Mar 15;26(6):841-2.

33. Marçais G, Kingsford C. A fast, lock-free approach for efficient parallel counting of 
occurrences of k-mers. Bioinformatics. 2011 Mar 15;27(6):764-70.

34. R Core Team. R: A Language and Environment for Statistical Computing. Vienna, Austria: R Foundation for Statistical Computing; 2020.

35. Contreras-Moreira B, Naamati G, Rosello M, Allen JE, Hunt SE, Muffato M, et al. Ensembl/plant-scripts. GitHub; 2021.

36. Jiménez-Ruiz J, Ramírez-Tejero JA, Fernández-Pozo N, Leyva-Pérez M de la O, Yan $\mathrm{H}$, Rosa $\mathrm{R}$ de la, et al. Transposon activation is a major driver in the genome evolution of cultivated olive trees (Olea europaea L.). Plant Genome. 2020 Mar 27;13(1):e20010.

37. Hibrand Saint-Oyant L, Ruttink T, Hamama L, Kirov I, Lakhwani D, Zhou NN, et al. A high-quality genome sequence of Rosa chinensis to elucidate ornamental traits. Nat Plants. 2018 Jun 11;4(7):473-84.

38. Badouin H, Gouzy J, Grassa CJ, Murat F, Staton SE, Cottret L, et al. The sunflower genome provides insights into oil metabolism, flowering and Asterid evolution. Nature. 2017 Jun 1;546(7656):148-52.

39. Ksouri N, Castro-Mondragón JA, Montardit-Tardá F, van Helden J, Contreras-Moreira $\mathrm{B}$, Gogorcena Y. Tuning promoter boundaries improves regulatory motif discovery in nonmodel plants: the peach example. PLANT PHYSIOLOGY. 2021 Jan 13;

40. Baud A, Wan M, Nouaud D, Anxolabehere D, Quesneville H. Traces of past transposable element presence in Brassicaceae genome dark matter. BioRxiv. 2019 Feb 18;

41. Altschul SF, Madden TL, Schäffer AA, Zhang J, Zhang Z, Miller W, et al. Gapped BLAST and PSI-BLAST: a new generation of protein database search programs. Nucleic Acids Res. 1997 Sep 1;25(17):3389-402.

42. Adler D, Kelly ST. vioplot: violin plot. 2020;

43. Hall TA. BioEdit: A User-Friendly Biological Sequence Alignment Editor and Analysis Program for Windows 95/98/NT. Nucleic Acids Symp Ser. 1999;41:95-8.

44. Vassetzky NS, Kramerov DA. SINEBase: a database and tool for SINE analysis. Nucleic Acids Res. 2013 Jan;41(Database issue):D83-9.

45. Ou S, Su W, Liao Y, Chougule K, Agda JRA, Hellinga AJ, et al. Benchmarking transposable element annotation methods for creation of a streamlined, comprehensive pipeline. Genome Biol. 2019 Dec 16;20(1):275.

46. Du J, Grant D, Tian Z, Nelson RT, Zhu L, Shoemaker RC, et al. SoyTEdb: a comprehensive database of transposable elements in the soybean genome. BMC Genomics. 2010 Feb 17;11:113.

47. Staton SE, Bakken BH, Blackman BK, Chapman MA, Kane NC, Tang S, et al. The sunflower (Helianthus annuus L.) genome reflects a recent history of biased accumulation of transposable elements. Plant J. 2012 Oct;72(1):142-53.

48. Natali L, Cossu RM, Barghini E, Giordani T, Buti M, Mascagni F, et al. The repetitive component of the sunflower genome as shown by different procedures for assembling next generation sequencing reads. BMC Genomics. 2013 Oct 6;14:686.

49. Castanera R, Ruggieri V, Pujol M, Garcia-Mas J, Casacuberta JM. An Improved Melon 
Reference Genome With Single-Molecule Sequencing Uncovers a Recent Burst of Transposable Elements With Potential Impact on Genes. Front Plant Sci. 2019;10:1815.

50. Legrand S, Caron T, Maumus F, Schvartzman S, Quadrana L, Durand E, et al. Differential retention of transposable element-derived sequences in outcrossing Arabidopsis genomes. Mob DNA. 2019 Jul 17;10:30.

51. Alioto T, Alexiou KG, Bardil A, Barteri F, Castanera R, Cruz F, et al. Transposons played a major role in the diversification between the closely related almond and peach genomes: results from the almond genome sequence. Plant $\mathrm{J}$. 2020;101(2):455-72.

52. International Brachypodium Initiative. Genome sequencing and analysis of the model grass Brachypodium distachyon. Nature. 2010 Feb 11;463(7282):763-8.

53. Zhang L, Cai X, Wu J, Liu M, Grob S, Cheng F, et al. Improved Brassica rapa reference genome by single-molecule sequencing and chromosome conformation capture technologies. Hortic Res. 2018 Aug 15;5:50.

54. De Vega JJ, Ayling S, Hegarty M, Kudrna D, Goicoechea JL, Ergon Å, et al. Red clover (Trifolium pratense L.) draft genome provides a platform for trait improvement. Sci Rep. 2015 Nov 30;5:17394.

55. Willing E-M, Rawat V, Mandáková T, Maumus F, James GV, Nordström KJV, et al. Genome expansion of Arabis alpina linked with retrotransposition and reduced symmetric DNA methylation. Nat Plants. 2015 Feb 2;1:14023.

56. Ruggieri V, Alexiou KG, Morata J, Argyris J, Pujol M, Yano R, et al. An improved assembly and annotation of the melon (Cucumis melo L.) reference genome. Sci Rep. 2018 May 24;8(1):8088.

57. Guo S, Zhang J, Sun H, Salse J, Lucas WJ, Zhang H, et al. The draft genome of watermelon (Citrullus lanatus) and resequencing of 20 diverse accessions. Nat Genet. 2013 Jan;45(1):51-8.

58. International Rice Genome Sequencing Project. The map-based sequence of the rice genome. Nature. 2005 Aug 11;436(7052):793-800.

59. Thielen PM, Pendelton AL, Player RA, Bowden KV, Lawton TJ, Wisecaver JH. Reference genome for the highly transformable Setaria viridis cultivar ME034V. BioRxiv. 2020 May 3;

60. Jaillon O, Aury J-M, Noel B, Policriti A, Clepet C, Casagrande A, et al. The grapevine genome sequence suggests ancestral hexaploidization in major angiosperm phyla. Nature. 2007 Sep 27;449(7161):463-7.

61. Raymond O, Gouzy J, Just J, Badouin H, Verdenaud M, Lemainque A, et al. The Rosa genome provides new insights into the domestication of modern roses. Nat Genet. 2018 Apr 30;50(6):772-7.

62. Kagale S, Koh C, Nixon J, Bollina V, Clarke WE, Tuteja R, et al. The emerging biofuel crop Camelina sativa retains a highly undifferentiated hexaploid genome structure. Nat Commun. 2014 Apr 23;5:3706.

63. Daccord N, Celton J-M, Linsmith G, Becker C, Choisne N, Schijlen E, et al. 
High-quality de novo assembly of the apple genome and methylome dynamics of early fruit development. Nat Genet. 2017 Jul;49(7):1099-106.

64. Unver T, Wu Z, Sterck L, Turktas M, Lohaus R, Li Z, et al. Genome of wild olive and the evolution of oil biosynthesis. Proc Natl Acad Sci USA. 2017 Oct 31;114(44):E9413-22.

65. Schnable PS, Ware D, Fulton RS, Stein JC, Wei F, Pasternak S, et al. The B73 maize genome: complexity, diversity, and dynamics. Science. 2009 Nov 20;326(5956):1112-5.

66. Zhao G, Zou C, Li K, Wang K, Li T, Gao L, et al. The Aegilops tauschii genome reveals multiple impacts of transposons. Nat Plants. 2017 Dec;3(12):946-55.

67. Maccaferri M, Harris NS, Twardziok SO, Pasam RK, Gundlach H, Spannagl M, et al. Durum wheat genome highlights past domestication signatures and future improvement targets. Nat Genet. 2019 Apr 8;51(5):885-95. 